\title{
TEN YEARS OF CORTICOSTEROIDS IN LOCAL INJECTION THERAPY
}

\author{
G. Holden, M.A., M.B., M.R.C.P.(Edin.), D.Phys.Med. \\ Senior Registrar, Department of Physical Medicine, Guy's Hospital, London
}

THE beginning of local corticosteroid injection therapy is now ten years behind us. We can with great advantage look back upon the past and assess this form of therapy with a decade of experience behind us. Ten years ago there was only hydrocortisone, now there is a wide choice of corticosteroids, some of which are superior to it.

The first reports on hydrocortisone acetate were made in 1951 by Hollander, Brown, Jessar and Brown. They found that a variety of lesions could be either cured outright, or much improved by a single local injection. The types of lesion which they found responsive were traumatic lesions of tendons, ligaments and joints, also non-septic arthritis or bursitis. In osteoarthritis a poor response was obtained unless recent trauma had led to symptoms. Since these early findings, others have added carpal tunnel compression, and some forms of backache and even sciatica, to the list of responsive lesions. On the whole the scope of this form of therapy has remained the same over the years.

Quoting the early experiences with hydrocortisone acetate it was found that an optimal response was obtained when a joint was injected, which could be reduced by over- or under-dosage. Thus, an optimal dose was established for each joint. Some $10 \%$ of lesions failed to respond to the local injection although similar lesions had responded. Some cases experienced marked post-injection pain, some arthritic joints became worse after injection, and a very few responded allergically to the injection. Of all these drawbacks the most important were the temporary worsening of the arthritis, the marked post-injection pain, and the failure to respond in Io per cent. of cases. The duration of improvement in joint symptoms and signs after injection proved a useful measure by which to compare other injections, particularly when there was a recurrence within a short period of time. These are the features which can be used to assess a new preparation for local injection therapy.

The success of hydrocortisone acetate led to the investigation of other esters and homologues of hydrocortisone. The esters tested included the benzoate, caprylate and the tertiary butyl acetate. $\vec{\circ}$ The two former esters were less effective than thetertiary butyl acetate, which was as effective in $\vec{\omega}$ some hands as the acetate. Pain at the time of $\frac{5}{0}$ injection, and a 10\% failure rate, however, were 3 drawbacks. Norcross (1958) showed that the bigger the injected dose, the longer the response, $\infty$ thus conflicting with the theory of an optimal te dose for each joint.

The homologues of hydrocortisone acetate $\stackrel{N}{\mathscr{C}}$ tested included the 9-alpha-chloro-hydrocortisone, $ᄋ$ fluoro-cortisone, and the allo-dihydro-hydrocortisone. Only fluoro-cortisone was effective, but $\vec{z}$ marked œdema due to fluid retention make it unsuitable for therapy. The next corticosteroid to be used was prednisolone acetate. This w\& introduced in 1954 in a suitable form for injection therapy. However, the equivalent dose to mg. of hydrocortisone acetate was found to be 10 $\mathrm{mg}$. of prednisolone acetate, instead of the expected $5 \mathrm{mg}$. This was only two-and-a-half times as potent as hydrocortisone acetate, and $\cong$ not five times as expected. The explanation for $\overrightarrow{0}$ this is probably a difference in solubility, resistance $\exists$ to local enzymes and actual potency. Using this corticosteroid Kendall (1958) found that the postinjection pain was less than with hydrocortisone, and that the duration of relief from joint symptoms was longer. The incidence of acute exacerbations was less also. These features made prednisolone a natural successor to hydrocortisone. Attempts to improve the duration of its action led to the production of the tertiary methyl acetate. Using this ester in $200 \mathrm{mg}$. doses injected into rheuma- $\rightarrow$ toid knees Cardoe (1959) showed that the frequency of injections could be much reduced. The $N$ possibility of systemic absorption was realized $N$ but no evidence to substantiate it was then available.

Steroid arthropathy has been described more $\stackrel{0}{<}$ recently in weight-bearing joints which although the site of an arthritis are not rested. The occur- $\mathbb{D}$ rence in osteoarthritic hip joints was described by Sweetnam (1960), a similar appearance was seen in rheumatoid knees by Chandler, Jones, Wright and Hartfall (1959). The cases described 
by both authors were given multiple injections of large doses of corticosteroid. We have seen one case where the joint affected had never been injected, but the patient had been for years on oral steroids. The two common factors in these cases are corticosteroid therapy, either oral or local, and continued weight-bearing. The incidence of this complication is very small, and estimated as $0.7 \%$ of all injected joints by Hollander, Brown, Jessar, Udell, Smuhler and Bowie (I96I). The radiological appearance is a destructive arthritis, with marked bone absorption and osteoporosis. Clinically, the joint is unstable, but relatively painless, like a Charcot's arthropathy. The incidence can possibly be reduced by avoiding multiple large injections, and ensuring adequate rest.

The next corticosteroid to be used in local injection therapy was dexamethasone. This was available as the phosphate, and as the tertiary butyl acetate. The phosphate had a short duration action which was rapid in onset, features which Christie (1959) had noted with the phosphate of prednisolone. The tertiary butyl acetate had a long action and was very effective, but Thompson (I96I) found that systemic absorption sufficient to enliven a peptic ulcer occurred.

Triamcinolone was the next newcomer. This corticosteroid was presented as the acetonide and the diacetate. These compounds had a high anti-inflammatory potency (Sperling, I960), but when compared with prednisolone by Holden and Kendall (1961), the latter was found to be superior.

Methyl prednisolone is the latest newcomer to the scene. This corticosteroid was presented as the acetate for local injection. The results show that this corticosteroid is very effective in lesions which have not responded to another steroid. The
TABle I

Preparations Available for Local, Injection

\begin{tabular}{|c|c|c|}
\hline Steroid & Ester & Concentratic \\
\hline Hydroc & Acetate & 25 \\
\hline & $\begin{array}{l}\text { Tertiary butyl } \\
\text { acetate }\end{array}$ & \\
\hline Prednisolone & Acetate & $25 \mathrm{mg} . /$ \\
\hline & $\begin{array}{l}\text { Tertiary methyl } \\
\text { acetate }\end{array}$ & $\begin{array}{l}\text { I } 5 \mathrm{mg} \cdot / \mathrm{ml} \text {. } \\
200 \mathrm{mg} . / \mathrm{ml} \text {. }\end{array}$ \\
\hline Prednisolone & Phosphate & $25 \mathrm{mg} \cdot / \mathrm{ml}$ \\
\hline Triamcinolone & Acetonide & I0 $\mathrm{mg} . / \mathrm{m}$ \\
\hline Triamcinolone & Diacetate & $20 \mathrm{mg} \cdot / \mathrm{m}$ \\
\hline Dexamethasone & Phosphate & $4 \mathrm{mg} \cdot / \mathrm{m}$ \\
\hline Dexamethasone & $\begin{array}{l}\text { Tertiary butyl } \\
\text { acetate }\end{array}$ & $4 \mathrm{mg} \cdot / \mathrm{r}$ \\
\hline Methyl prednisolone & Acetate & $40 \mathrm{mg} . /$ \\
\hline
\end{tabular}

duration of response in the chronic arthritides is also longer than with prednisolone acetate, and there was less post-injection pain. However, there was evidence of systemic absorption and adrenal suppression in two cases described by Holden and Kendall (196r).

The number of corticosteroids is now becoming larger, and the various esters of these appearing in a suitable medium for local injection therapy is even more numerous. There is probably need for three preparations in clinical practice. The first should be an effective, cheap injection for curable lesions, such as 'tennis elbow'; this is prednisolone acetate or hydrocortisone acetate.? Should resistance to this steroid be found then a second preparation is advisable; this could be methyl prednisolone. For chronic arthritis requiring frequent injections, then a long-acting preparation is needed, such as prednisolone tertiary methyl acetate, given as a large dose of 100-200 mg., but not repeated more often than every six weeks at the most.

\section{REFERENCES}

Cardoe, N. (1959): The Injection of Concentrated Prednisolone Trimethylacetate Intra-Articularly in Rheumatoid Arthritis, Proc. roy. Soc. Med., 52, I 109.

Chandler, G. N., Jones, D. T., Wright, V., and Hartfall, S. J. (1959): Charcot's Arthropathy following IntraArticular Hydrocortisone, Brit. med. $\mathcal{F}$., i, 952.

Christie, B. G. B. (1959): Intra-articular Prednisolone 21-Phosphate: A Clinical Trial, Lancet, i, 7 I.

Holden, G., and Kendall, P. H. (196I): The Newer Corticosteroids in Local Injection Therapy, Ann. phys. Med., $6,178$.

Hollander, J. L., Brown, E. M., Jessar, R. A., and Brown, C. Y. (195I): Hydrocortisone and Cortisone Injected into Arthritic Joints, F. Amer. med. Ass., 147, 1629.

- - - - - - Udell, L., Smuhler, N., and Bowie, M. A. (ig6r): Bull. rheum. Dis., 5, 239.

Kendall, P. H. (1958): Intra-articular Prednisolone, Brit. med. F., ii, 290.

Norcross, B. M. (1958): Intra-articular Administration of Hydrocortisone in High Concentration, F. Amer. med. Ass., 167,839 .

Sperling, I. L. (1960): Intra-articular Steroid Therapy with Triamcinolone Acetonide in Low Dosage, Postgrad. Med., $27,232$.

Sweetnam, R. (i 960): Cortisone Arthropathy of the Hip, Proc. roy. Soc. Med., 53, 63.

Thompson, M. (196r): Dexamethasone Esters in Intra-articular and Soft Tissue Injections, Ann. phys. Med., 6, ro. 